THIS PAPER IS PUBLISHED IN THE PROCEEDINGS OF THE ASCE

STRUCTURES CONFERENCE, PORTLAND, OREGON (APRIL 2015)

\title{
Collapse Analysis and Testing of an Existing Building
}

\author{
Halil Sezen ${ }^{1}$ and Ebiji A. Akah ${ }^{2}$ \\ ${ }^{1}$ Professor, Department of Civil, Environmental and Geodetic Engineering, Ohio State \\ University, 470 Hitchcock Hall, 2070 Neil Avenue, Columbus, OH 43210-1115, PH \\ (614) 292-1338; email: sezen.1@ osu.edu \\ ${ }^{2}$ M.S. Civil Engineering Student, Department of Civil, Environmental and Geodetic \\ Engineering, Ohio State University, PH (614) 596-7597; email: akah.6@osu.edu
}

\begin{abstract}
Very limited full-scale experiments have been conducted to understand the mechanism of progressive collapse, which involves partial or complete collapse of a structure typically due to the loss of a vertical load carrying element(s). Progressive collapse design guidelines recommend simplified analysis procedures involving instantaneous removal of specified critical columns in a building. This research investigates the effectiveness of such commonly used methodologies by testing the vulnerability of an existing steel building on the Ohio State University campus. One first-story column was removed from the buiTHlding to understand how the loads are redistributed. Deflections and strains within the neighboring beams and columns were measured during column removal. Experimental data from the field test were compared with data from structural analysis. The main conclusion is that more than $70 \%$ of the loads applied on the removed column are redistributed within the perimeter frame; the remaining loads are carried by the interior columns after the column is removed.
\end{abstract}




\section{THIS PAPER IS PUBLISHED IN THE PROCEEDINGS OF THE ASCE}

STRUCTURES CONFERENCE, PORTLAND, OREGON (APRIL 2015)

\section{INTRODUCTION}

Progressive collapse can be defined as partial or complete collapse of a structure due to a small or local structural failure usually involving loss of a vertical load carrying element such as a column. When the column is lost, the load that the column supports is then distributed through the structure into nearby slabs, beams and columns until equilibrium is once again obtained. When the neighboring elements are not designed to redistribute the load, a disproportionate part of the structure could collapse. The General Services Administration (GSA), American Society of Civil Engineers (ASCE), and the Unified Facility Criteria (UFC) have guidelines to evaluate, design and improve progressive collapse resistance of existing and new buildings. GSA (2003) outlines procedures to evaluate whether a building, based on its size and shape, is vulnerable to progressive collapse. ASCE 7 (2010) outlines approaches to ensure structural integrity when a load-carrying member is damaged. Lastly, UFC 4-023-03 outlines how to prevent progressive collapse in multi-story buildings (DOD 2005). This research will use these guidelines to test and analyze whether the existing test structure was susceptible to progressive collapse.

\section{BUILDING DESCRIPTION}

This research focuses on progressive collapse modeling and analysis of Haskett Hall, which was a four-story building built in 1925 on the main campus of the Ohio State University (OSU) in Columbus, Ohio. The building consisted of classrooms, offices and laboratories. A section on the North side of the building was used as a three-

story testing laboratory (Figure 1). The building included a grid of seven columns in 
THIS PAPER IS PUBLISHED IN THE PROCEEDINGS OF THE ASCE

STRUCTURES CONFERENCE, PORTLAND, OREGON (APRIL 2015)

the North-South direction and six columns in the East-West direction, with a total of 38 primary columns that spanned the height of the building.

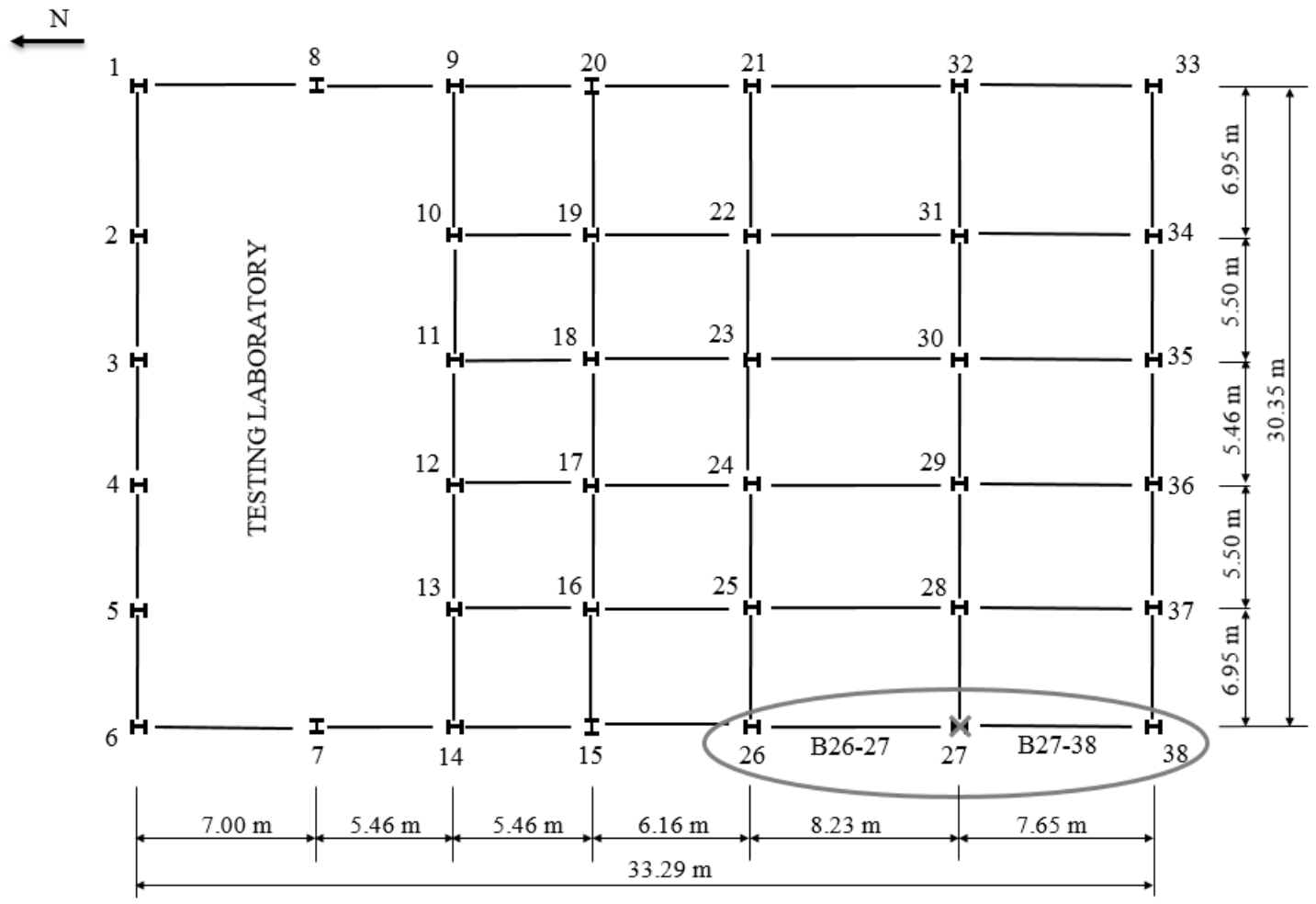

Figure 1. Haskett Hall plan view with testing area circled

Materials. Structural materials included built-up steel columns, reinforced concrete floor slabs, and steel I-beams encased with concrete (Figure 2.a). The built-up columns were I-sections bracketed by two channel sections connected with eight rivets. The first story columns were connected rigidly to the foundation with rivets and angles, thus they are modeled with fixed ends at the base. Beams and columns consisted of A36 steel with specific yield strength of $36 \mathrm{ksi}$ (248 MPa). Beams were connected to columns using rivets through angles that were attached to the bottom flanges and webs of the beams. Reinforced concrete slabs and encased steel beams had $4 \mathrm{ksi}$ (27.6 MPa) 
concrete, with assumed composite action. Furthermore, steel beams located in the perimeter frames were partially encased in concrete for fireproofing (Figure 2.b). Pouring the concrete in the slab and encased beam together creates a monolithic concrete that is appropriate to model as a single material.

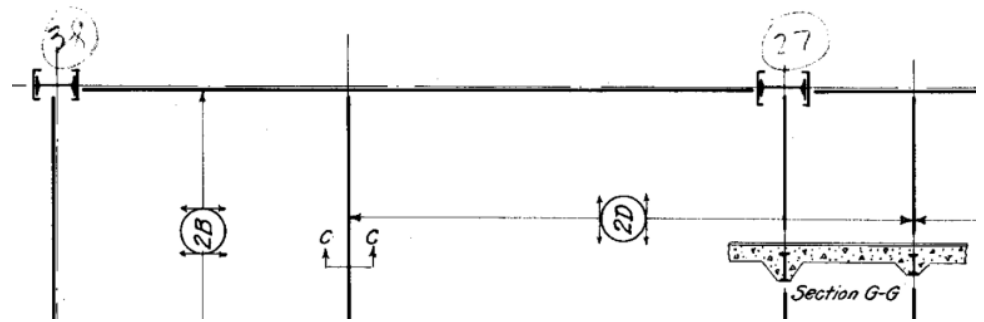

(a)

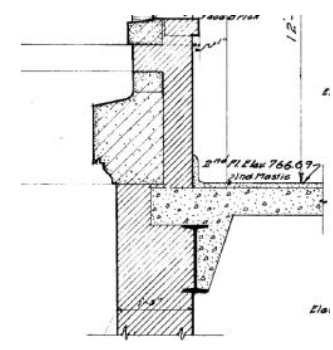

(b)

Figure 2. (a) testing area with built-up columns 27 and 38 (circled in Figure 1), and (b) partially encased perimeter beam.

Floor systems. The second floor included numerous beam systems to support a 7 in. $(178 \mathrm{~mm})$ reinforced concrete slab. The third and fourth floors were similar in layout. Both upper floors had secondary beams that ran mainly in the East-West direction, and trapezoidal concrete joists that resided under floor slabs to create one-way slab action. Joists were typically spaced at $25 \mathrm{in}$. (635 $\mathrm{mm})$ while upper floor slabs were typically 2.5 in. $(63.5 \mathrm{~mm})$ deep. Roof elevations slightly varied between the North and South sides of the building, but were assumed to be at a constant average elevation in computer models. The roof consisted of a wood tongue and a gravel deck. Numerous channel purlins in the East-West direction created one-way slab action between NorthSouth directed beams. The uniformly distributed roof load is $174 \mathrm{lb} / \mathrm{ft}(259 \mathrm{~kg} / \mathrm{m})$, which corresponds to combining deck and purlin loads. 
THIS PAPER IS PUBLISHED IN THE PROCEEDINGS OF THE ASCE

STRUCTURES CONFERENCE, PORTLAND, OREGON (APRIL 2015)

Frame elements. The Western frame elevation and bay dimensions, based on beam and column centerlines, and applied loads are shown in Figure 3. Beam sizes were provided in the original plan drawings. Column sizes were determined from pictures taken onsite during the experiment and confirmed with the historical AISC channel and I sections (Table 1).

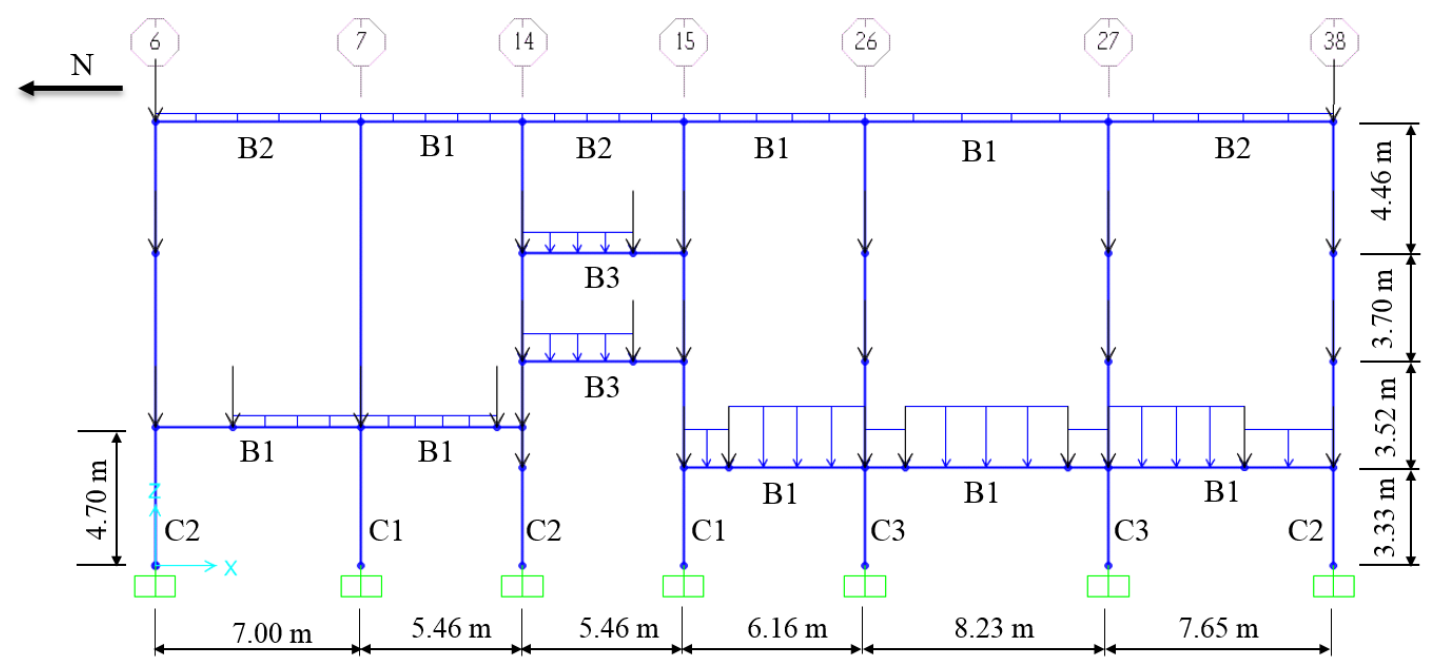

Figure 3. Western frame computer model.

Table 1. Column and beam assignments.

\begin{tabular}{lll} 
Column & I-section & Channels \\
\hline $\mathrm{C} 1$ & $\mathrm{~S} 12 \times 45$ & $\mathrm{C} 13.0 \times 3.0 \times 0.5$ \\
$\mathrm{C} 2$ & $\mathrm{~S} 15 \times 81.3$ & $\mathrm{C} 13.5 \times 3.0 \times 0.5$ \\
$\mathrm{C} 3$ & $\mathrm{~S} 20 \times 90$ & $\mathrm{C} 15.5 \times 4.0 \times 0.5$ \\
\hline Beam & I-section & \\
$\mathrm{B} 1$ & $\mathrm{~B} 15 \times 42$ & \\
$\mathrm{~B} 2$ & $\mathrm{~B} 18 \times 55$ & \\
$\mathrm{~B} 3$ & $\mathrm{~B} 24 \times 73.5$ & \\
\hline
\end{tabular}


THIS PAPER IS PUBLISHED IN THE PROCEEDINGS OF THE ASCE

STRUCTURES CONFERENCE, PORTLAND, OREGON (APRIL 2015)

Exterior walls. The exterior of the building had a masonry skin combining brick and limestone (Figure 2.b). Floor slabs rested on the exterior floor beams and extended into the façade. Limestone extended above floor beams and slabs and provided architectural designs along the façade. The brick extended above the limestone until the next floor beam. The combined density of the exterior walls is assumed to be $101 \mathrm{lb} / \mathrm{ft}^{3}(1618$ $\left.\mathrm{kg} / \mathrm{m}^{3}\right)$. As an example, the uniformly distributed wall load is $889 \mathrm{lb} / \mathrm{ft}(1323 \mathrm{~kg} / \mathrm{m})$, which corresponds to 13 in. (330 mm) wall thickness and 144 in. (3656 mm) wall height in the second floor.

\section{INSTRUMENTATION AND TESTING}

The experiment focused on the Western frame of the building (Figure 3). One column - labeled 27 in original building drawings (Figures 1 and 2.a) - was removed from the first-story of Haskett Hall within a short time period, as recommended by the GSA design guidelines (GSA 2003). A total of 16 strain gauges were used to measure the change in axial strains during the column removal. Seven strain gauges were attached to the three neighboring columns while nine strain gauges were attached on the neighboring beams. Figure 4 shows the columns that were instrumented with strain gauges: one corner column to the South, one column along the face of the building to the North and one interior column to the East that is out of view. 
THIS PAPER IS PUBLISHED IN THE PROCEEDINGS OF THE ASCE STRUCTURES CONFERENCE, PORTLAND, OREGON (APRIL 2015)

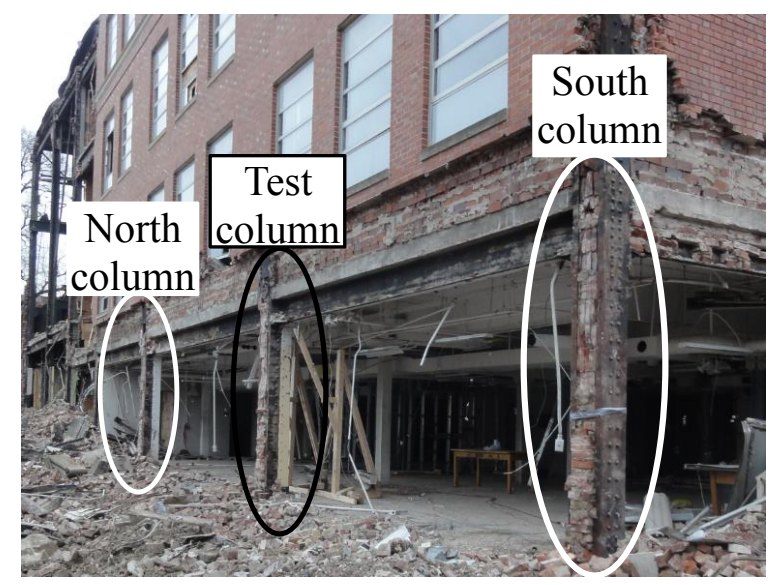

Figure 4. Neighboring columns instrumented with strain gauges.

Strain gauges. The columns that were instrumented with strain gauges - located to the North, East, and South of the test column - were labeled 26, 28 and 38, respectively. Column 38, the corner column located to the South of the removed column, had four strain gauges. For example, gauge \#7 was attached on the North flange face at one-half height of the Column 38 (55 in. or $1397 \mathrm{~mm}$ above base). All strain gauges located on beams were on the bottom face of flanges. The orientation of each strain gauge was parallel to the beam's longitudinal direction and located on the centerline or no more than 2 in. $(50 \mathrm{~mm})$ off-center. The beams connected to the removed column in the North-South direction each had three strain gauges.

Displacement sensors. Along with the 16 strain gauges, three Linear Variable Differential Transformers (LVDTs) were used to collect vertical and horizontal displacement measurements surrounding the removed column. During the experiment, two LVDTs were used to measure vertical displacements - one to the North and one to the South of the removed column. The North LVDT was placed 18 in. $(460 \mathrm{~mm})$ from the removed column, while the South LVDT was placed $28.75 \mathrm{in} .(730 \mathrm{~mm})$ away. The 
THIS PAPER IS PUBLISHED IN THE PROCEEDINGS OF THE ASCE STRUCTURES CONFERENCE, PORTLAND, OREGON (APRIL 2015)

third LVDT was placed on the North side of the test column in the horizontal direction to measure any potential slippage at the bottom of the beam-column connection. To hold the two vertical LVDTs right under the beams connected to the removed column's North and South faces, two wooden towers were used (Figure 5).

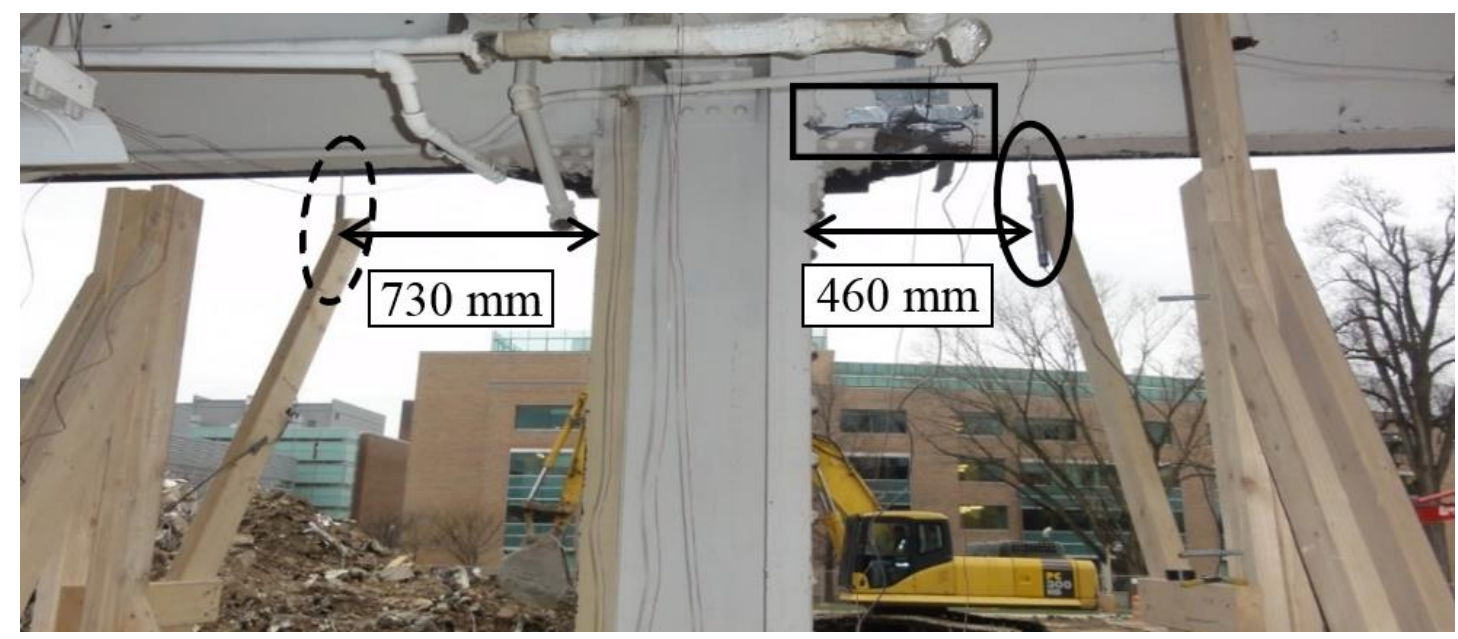

Figure 5. Vertical LVDTs to the South (dashed) and North (solid) and horizontal LVDT (rectangle) around the removed column.

Column removal. To remove the column, the demolition company first removed the walls on each side of the test column. At this time, the columns and beams were instrumented with strain gauges. To remove the column, the demolition company used a processor - a machine that has a claw to twist, pull and pinch a column (Figure 6.a). While the column was being cut through (Figure 6.b), the data measured by the strain gauges and displacement sensors were being collected by a laptop and a portable data acquisition system. The Interagency Security Committee (ISC) provides required levels of protection for progressive collapse of a rigid steel frame structure with a frangible façade. To abide by the highest ISC level of protection, all researchers 
THIS PAPER IS PUBLISHED IN THE PROCEEDINGS OF THE ASCE STRUCTURES CONFERENCE, PORTLAND, OREGON (APRIL 2015)

retained a minimum defended standoff distance of $100 \mathrm{ft}(30 \mathrm{~m})$ away from the test building (GSA 2003). Instrumentation and testing procedures followed in this experiment were similar to those used in previous OSU research (Song et. al 2013; Morone and Sezen 2014).

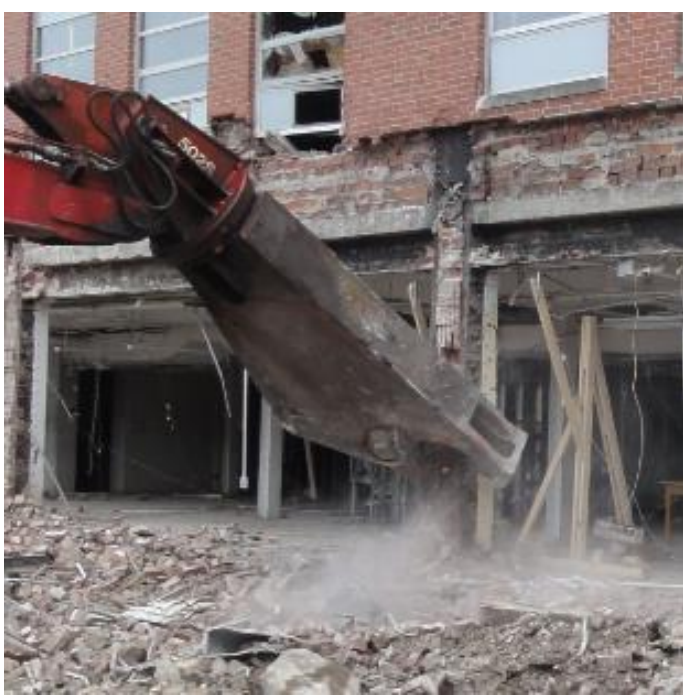

(a)

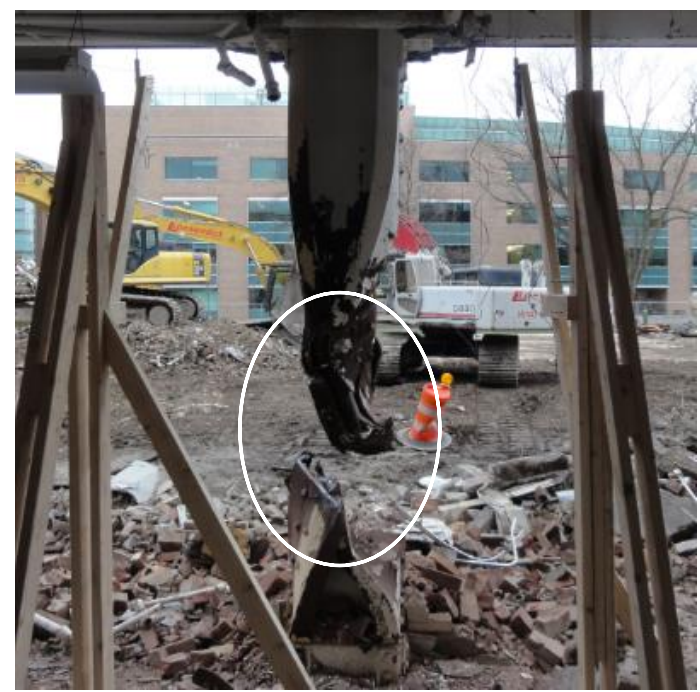

(b)

Figure 6. (a) processor cutting the column and (b) removed first-story column.

\section{EXPERIMENTAL DATA}

Strain data. When a structural element experiences positive strain, that element is being stretched under tensile force. Strain is negative under compressive force. After the processor pinched the column five distinct times, the column was cut through. Figure 7 displays an example plot of strain gauge \#7 with the five processor contact times numbered in italics. 
THIS PAPER IS PUBLISHED IN THE PROCEEDINGS OF THE ASCE STRUCTURES CONFERENCE, PORTLAND, OREGON (APRIL 2015)

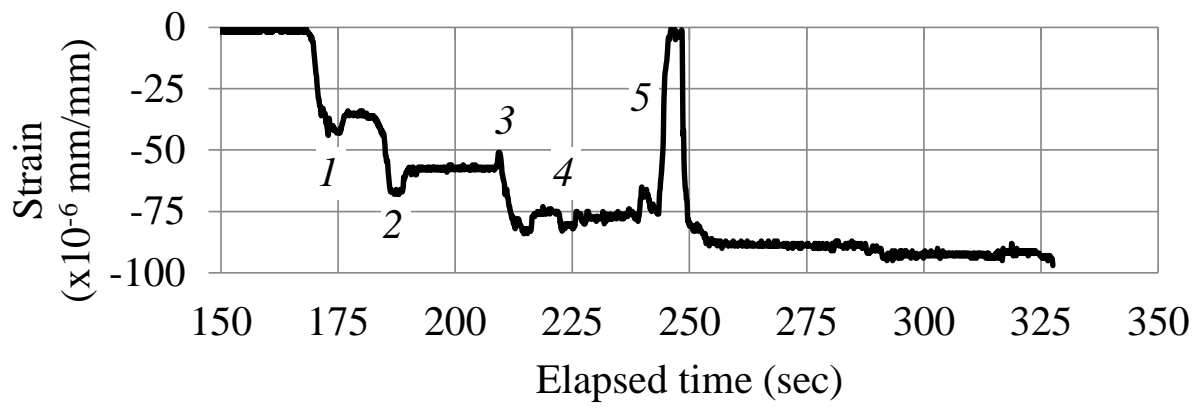

Figure 7. Strain versus time plot from gauge \#7 on South column 38.

Figure 7 shows that the processor did not make contact with the column until 168 seconds into data recording, and the column was cut through at the end of 252 seconds. At 300 seconds, Column 38 experienced a permanent compressive strain of approximately $-93 \times 10^{-6}$ at its mid-height, where gauge \#7 was located. Axial loads transferred from the test column to the neighboring columns created compressive strains in all neighboring columns.

Displacement data. Dynamic displacement data was recorded by the three displacement sensors during column removal process. Initially, all displacement sensors had stable readings, ideally at zero displacement. When the processor made contact with the test column, displacement values started to increase in the downward (negative) direction. The North sensor measured a permanent displacement of 0.474 in. $(12.03 \mathrm{~mm})$ and the South sensor recorded a permanent displacement of $0.659 \mathrm{in}$. $(16.74 \mathrm{~mm})$. Horizontal sensor measured $5.906 \times 10^{-3}$ in. $(0.15 \mathrm{~mm})$ at 300 seconds (Figure 8), which indicates that there was almost no slippage in the beam-column connection at the bottom face of the beam. Five processor contact times are numbered in italics in Figure 8. The negative vertical displacement values indicate the beams 
THIS PAPER IS PUBLISHED IN THE PROCEEDINGS OF THE ASCE

STRUCTURES CONFERENCE, PORTLAND, OREGON (APRIL 2015)

deflecting downward on both sides of the removed column in the North-South direction. In-depth experimental details and measurements can be found in Akah (2013).

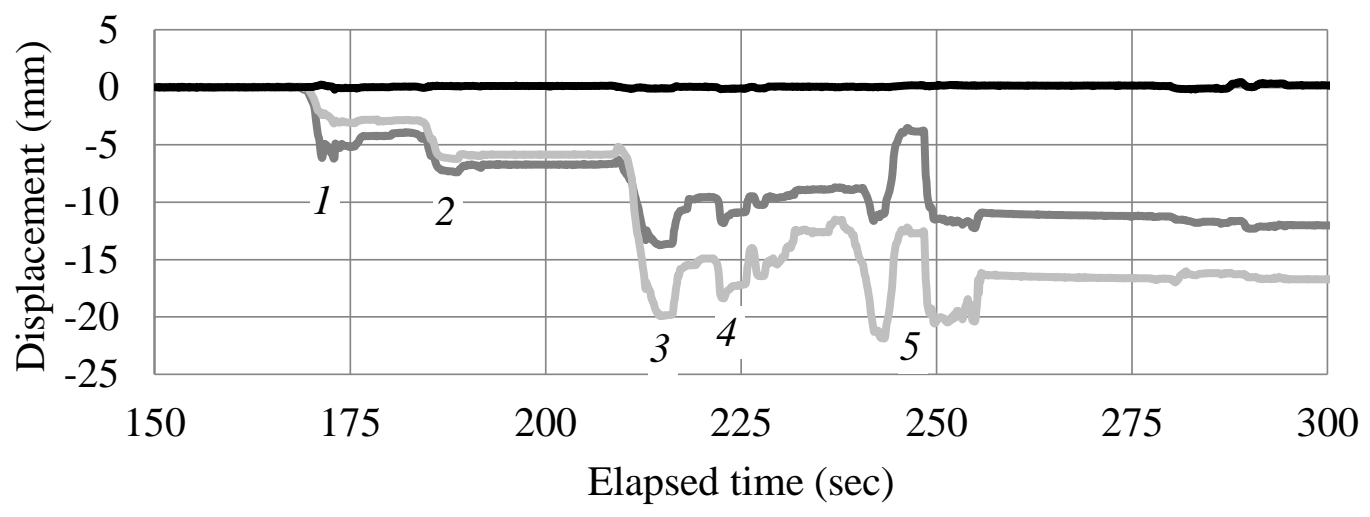

Figure 8. Displacement history measured by the South vertical (light grey), North vertical (grey), and horizontal (black) LVDTs.

\section{STRUCTURAL MODELING}

The western perimeter frame of Haskett Hall was modeled in the computer program SAP2000 (2012) to analyze progressive collapse performance by following GSA guidelines (Figure 3). Cross sectional dimensions of beams and columns are based on the sections given in Table 1. Floor elevation is assumed to be at the neutral axes of composite sections of beams along the frame. It was assumed that each member has a rigid offset of 1 .

Loads. All loads on the western frame were dead loads assigned by category: floor slab, floor joists, 3-D beam, interior walls, superimposed, and exterior walls. The category "3-D beam" signifies the concentrated loads from transverse beams framing 
THIS PAPER IS PUBLISHED IN THE PROCEEDINGS OF THE ASCE STRUCTURES CONFERENCE, PORTLAND, OREGON (APRIL 2015)

into the two-dimensional perimeter frame. To distribute loads to the frame, all tributary areas were assumed to hold one-way action near the perimeter frame. In terms of loads from floor slabs, floor joists, interior walls and superimposed loads, most of the tributary loads were transferred to the modeled exterior frame as concentrated loads due to the few beams that ran along the frame. Before the experiment, the demolition company removed a part of the perimeter façade, exposing the northern side of the western frame and the second floor beams along the frame (Figure 4). By removing the wall, this resulted in those areas of the frame having no exterior wall loads. Calculated external wall loads can be found in Wade (2013).

Composite action. Three different two-dimensional cross sections are used in SAP2000 to account for composite response of the beams along the frame. As the roof deck was composed of wood and gravel instead of concrete, roof beams did not have composite sections. Type 1 beams were used as a control, being designed as noncomposite (NC) (Figure 9.a). Type 2 beams carried the concrete overlay (CO) to represent the concrete floor deck (Figure 9.b). Type 3 beams were designed with the concrete deck and concrete-filled web (CFW) of the steel beam (Figure 9.c).

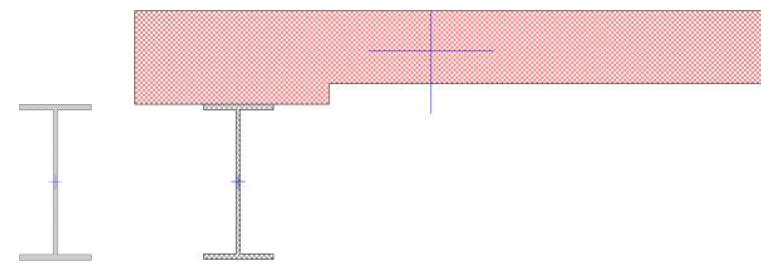

(a) (b)

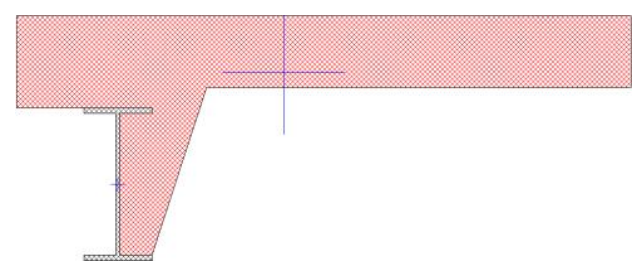

(c)

Figure 9. (a) non-composite, (b) concrete overlay, and (c) concrete-filled web. 
THIS PAPER IS PUBLISHED IN THE PROCEEDINGS OF THE ASCE

STRUCTURES CONFERENCE, PORTLAND, OREGON (APRIL 2015)

For each composite beam, the effective width of the reinforced concrete slab was determined by using the appropriate equations from the American Concrete Institute code 318 (ACI 318 2011). As composite cross-sections increase the weight of the beam, all analyses ignored the self-weight of the frame by setting all load pattern selfweight multipliers to 0 .

\section{ANALYSIS}

Linear static and linear dynamic time history analyses were used to verify the displacements resulting from removing the column. Because the natural response of the building is dynamic, the time history analyses capture a more accurate response. To run a dynamic analysis, the primary step is determining the forces and moments located at the connecting joint of the removed column when the column is still intact. These values are considered "equivalent" values. Next, the equivalent values are applied to the joint when the column is removed to reenact initial equilibrium. Lastly, the same equivalent load values are suddenly reduced to zero as part of the load input function to simulate the sudden column removal (Song and Sezen 2013, and Morone and Sezen 2014).

Displacement comparison. Experimental data from the building is compared with data calculated from SAP2000 as a result of the first-story column removal. The two vertical displacement sensors (LVDTs) were used to measure displacement under the North- and South-directed beams connected to the test column 27. As seen in Figure 5, the distances of these two LVDTs were measured onsite from the external face of the column section instead of the column's neutral axis. To compare the displacement at the column neutral axis in SAP2000, the experimental displacement was estimated by 
THIS PAPER IS PUBLISHED IN THE PROCEEDINGS OF THE ASCE

STRUCTURES CONFERENCE, PORTLAND, OREGON (APRIL 2015)

assuming a linear displacement variation between the two vertical LVDT measurements on each side of the column. This average measured displacement at column neutral axis is compared with the displacements calculated from SAP2000 analyses (Table 2).

Table 2. Comparison of experimental and calculated displacements

Beam section

Non-Composite (NC)

Concrete Overlay $(\mathrm{CO})$

Concrete-Filled Web (CFW)

Experimental
Displacement (mm)

$-227.7$

$-84.2$

$-66.9$

$-16.2$

Calculated displacements drastically exceed the experimental measurements. Clearly the accuracy improves when the composite action is included and hence the beam stiffness is increased. The large deflections calculated from SAP2000 models suggests a low level of rigidity. Once the column was removed, the continuous beam has limited strength and stiffness to redistribute and transfer large axial column and floor loads and counteract deflections. The deflections calculated in these preliminary twodimensional analyses indicate the importance of: 1) three-dimensional models and analyses to consider load redistribution both within the perimeter frame (as in 2-D analyses in this paper) as well as inside the building in the transverse direction, and 2) contribution of floor slabs for a more rigid and accurate representation of the 3-D building behavior. 
THIS PAPER IS PUBLISHED IN THE PROCEEDINGS OF THE ASCE

STRUCTURES CONFERENCE, PORTLAND, OREGON (APRIL 2015)

Demand-capacity ratios. GSA (2003) uses Demand-Capacity Ratios (DCRs) to determine which elements will exceed their load carrying capacity and lead to progressive collapse. DCR is defined as the maximum internal force calculated from linear elastic static analysis, e.g., maximum moment $M_{\max }$, divided by the maximum capacity, e.g., moment strength $M_{p}$, of the member cross section (Equation 1).

$$
D C R=\frac{2 M_{\max }}{M_{P}}
$$

In Equation 1, the 2.0 multiplier is based on the GSA guidelines to account for dynamic amplification effects. If DCR values for a given member exceed 2.0 for columns or 3.0 for beams, then the member is considered susceptible to failure (GSA 2003). The ultimate moment capacity, $M_{p}$, is equal to the product of the plastic modulus and yield strength of a steel member. The calculated DCR values for the beams and columns neighboring the removed column are shown in Table 3.

Table 3. DCR values for beams and columns neighboring the removed column.

Column number 26 38

Beam number

B26-27

B27-38
NC

0.34

0.61

NC

5.96

6.24
CO

0.94

1.55

CO

2.43

2.33
CFW

0.97

1.55

Table 3 shows that as the beam stiffness increases, through composite action, column DCR values increase while the beam DCR values decrease. Type 1 beams - non- 
THIS PAPER IS PUBLISHED IN THE PROCEEDINGS OF THE ASCE

STRUCTURES CONFERENCE, PORTLAND, OREGON (APRIL 2015)

composite (NC) - appear to be susceptible for failure because the calculated DCRs are larger than 3.0. Type 2 and 3 beams - concrete overlay (CO) and concrete-filled webs (CFW), respectively - satisfy the GSA DCR limits for both beams and columns in those respective 2-D frame models. The drastic range in calculated beam DCR values between composite and non-composite sections is mainly due to the change in plastic moduli for each beam. For example, the plastic modulus for non-composite beam B2627 is 70.6 in. $^{3}\left(1157 \mathrm{~cm}^{3}\right)$ and for Type 3 composite beam is $375.5 \mathrm{in}^{3}\left(6154 \mathrm{~cm}^{3}\right)$. The moment diagram for the frame with composite beams (CFW) and calculated DCR values can be seen in Figure 10. Overall, the calculated large DCR further support the necessity of three-dimensional modeling for the purpose of distributing loads more accurately and increasing the rigidity of the analyzed model by considering effects of strength and stiffness contributions of floor slabs and beams in the transverse direction.

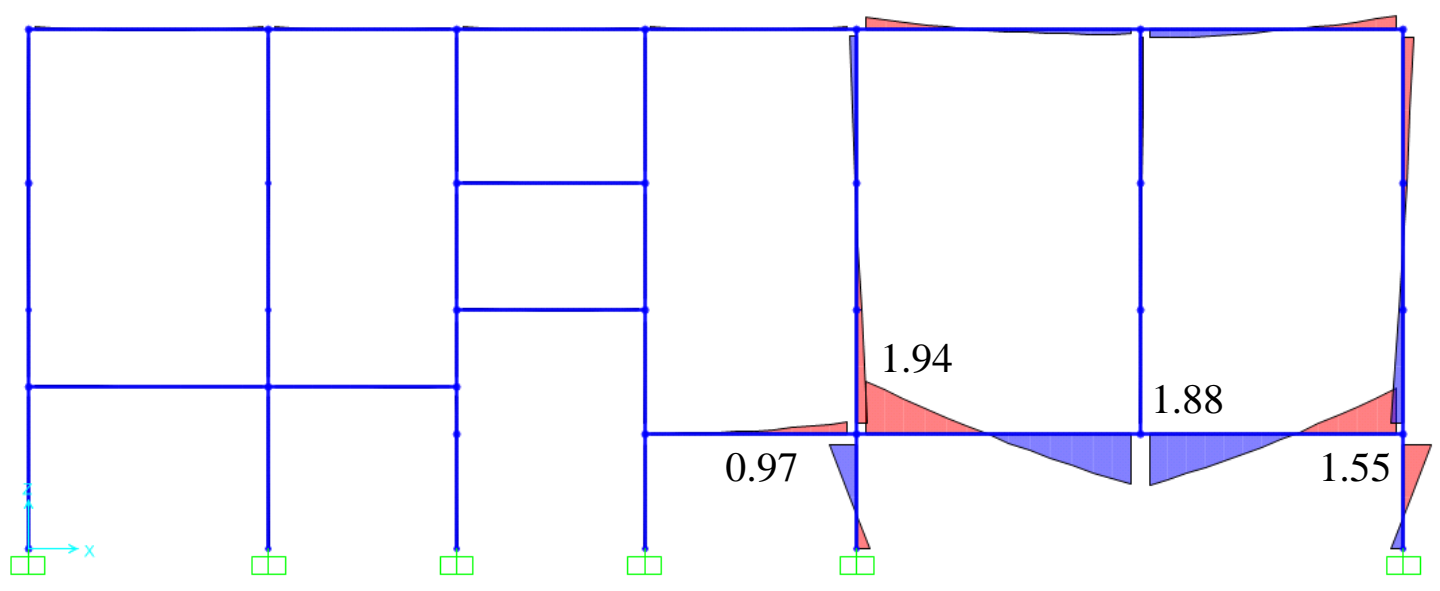

Figure 10. DCRs and moment diagram for frame with Type 3 (CFW) beams. 
THIS PAPER IS PUBLISHED IN THE PROCEEDINGS OF THE ASCE

STRUCTURES CONFERENCE, PORTLAND, OREGON (APRIL 2015)

\section{CONCLUSIONS}

An existing four-story steel building, Haskett Hall, was instrumented and physically tested by removing one of the first-story columns from the perimeter frame. The building was designed and completed in the 1920s, with some structural additions over the years. This created a challenge for the determination of material, loading, and geometric properties. Preliminary two-dimensional SAP2000 models are tested with linear static analyses with a focus on verification of displacements and DCR values. Comparison of analysis and experimental results showed that the SAP2000 results drastically exceeded the field results. This is mainly due to three-dimensional slab and load redistributions are not considered in the 2-D model. In addition, nonlinear and dynamic analyses should further improve the accuracy of the simulations.

\section{ACKNOWLEDGMENTS}

This research was partially funded by the National Science Foundation (CMMI 1130397) and American Institute of Steel Construction. This is gratefully acknowledged. The authors would like to thank graduate students involved in this research including Shadab Lodhi, Curtis Wood, John Wade, and Nick Savage. The authors also would like to thank Loewendick Demolishing Contractors, and The Ohio State University for providing access to the test building and help with the experiment. 
THIS PAPER IS PUBLISHED IN THE PROCEEDINGS OF THE ASCE

STRUCTURES CONFERENCE, PORTLAND, OREGON (APRIL 2015)

\section{REFERENCES}

ACI 318-11. (2011). Building code requirements for structural concrete and commentary. American Concrete Institute (ACI). Farmington Hills, MI.

Akah, E. A. (2013). "Progressive collapse testing and analysis of a steel building." (Undergraduate Honors Thesis), Department of Civil, Environmental and Geodetic Engineering, The Ohio State University, Columbus, $\mathrm{OH}$

ASCE 7-10. (2010). Minimum design loads for buildings and other structures. Report: ASCE/SEI 7-10. American Society of Civil Engineers (ASCE). Reston, VA.

DOD. (2005). Design of buildings to resist progressive collapse. Unified Facilities Criteria (UFC) 4-023-03, Department of Defense (DOD)

GSA. (2003). Progressive collapse analysis and design guidelines for new federal office buildings and major modernization projects. General Services Administration (GSA). Washington, D.C. 95

Morone D. J., and Sezen H. (2014). "Simplified collapse analysis using data from building experiment”. ACI Structural Journal. 111 (4): 925-934.

SAP2000. (2012). SAP 2000 Advanced structural analysis program, Version 15. Computers and Structures, Inc. (CSI). Berkeley, CA, U.S.A.

Song, B. I., and H. Sezen. (2013). "Experimental and analytical progressive collapse assessment of a steel frame building". Engineering Structures. 56: 664-672.

Song, B. I., Giriunas K. A., and Sezen H. (2014). "Progressive collapse testing and analysis of a steel frame building". Journal of Constructional Steel Research. 94 (3): 76-83. 
THIS PAPER IS PUBLISHED IN THE PROCEEDINGS OF THE ASCE

STRUCTURES CONFERENCE, PORTLAND, OREGON (APRIL 2015)

Wade, J. (2013). "Analysis of an existing building for progressive collapse by column removal." (Undergraduate Honors Thesis), Department of Civil, Environmental and Geodetic Engineering, The Ohio State University, Columbus, $\mathrm{OH}$ 